\title{
The Clinical Utility of the Concept of Mental Hygiene in the Behavioral Treatment of Depression
}

\author{
Carlos Carona and Ana Fonseca \\ University of Coimbra, Portugal
}

Mental hygiene has been traditionally regarded as a subdomain of public health and preventive medicine. The Encyclopædia Britannica defines mental hygiene as the science of maintaining mental health and preventing the development of mental disorders. The concept seems to have reached its preeminence in the middle of the $20^{\text {th }}$ century as a revolutionary trend in public health, despite the lack of a clear and informative definition.

Depression is the most common disorder worldwide and its prevalence is expected to increase in the upcoming years. Behavioral activation (BA) is one of the most well-established, time-efficient psychological treatments for depression (Chartier \& Provencher, 2013; Lorenzo-Luaces \& Dobson, 2019; Stein et al., 2020). Given the fact that it does not require therapists or patients to learn complex methods and skills, BA may be considered a first-line treatment for mild to moderate depression. BA is a therapeutic model grounded in the classical behavioral theories for the understanding and treatment of depression, developed by Wolpe and colleagues in the 1970s. BA posits that depressed individuals increasingly disengage from their routines and withdraw from their social environment, thus developing avoidance patterns that increase depressive mood by restricting a person's opportunities to be positively reinforced by pleasant, social, or mastery activities. BA adopts an ideographic (not a nomothetic) approach in identifying a person's values to map the schedule of activities, but also targets problem-solving skills and the cognitive-behavioral processes inhibiting engagement and promoting avoidance. In sum, BA involves activity monitoring, values and goals assessment, activity scheduling, skills training, relaxation, contingency management, procedures targeting verbal behavior, and strategies targeting avoidance (Jacobson et al., 2001; Lejuez et al., 2001). Therefore, a clinical concept of mental hygiene could assist life area assessment and the training of healthy behaviors (as opposed to depressive behaviors), which are crucial features across BA treatment plans.

From a clinical and evolutionary perspective, we propose that mental hygiene is the process of caring for human well-being through adaptive emotion regulation, successful attainment of developmental tasks, and the preservation of social connectedness (sense of belonging). Accordingly, the theoretical underpinnings of the proposed conceptualization of mental hygiene comprise a number of tenets: first, mental health is understood as the variable result from the ongoing interaction between an active organism and a dynamic context (Cummings et al., 2000); second, mental health encompasses the dimensions of life satisfaction, positive affect, anxiety, and depression (Headey et al., 1993); third, positive mental health is closely related to flourishing (i.e., spiraling upward) processes (Keyes, 2002); fourth, mental health is evolutionarily rooted in affiliative motives for the satisfaction of universal biosocial needs and requires the development of compassionate mind attributes (e.g., sensitivity, tolerance to distress, care for well-being) (Gilbert, 2015); and lastly, mindful self-care dimensions (i.e., physical care, supportive relationships, mindful awareness, self-compassion and purpose, mindful relaxation, supportive structure) are key predictors of well-being (Sünbül et al., 2018).

As a working definition, we further suggest that a scientifically based construct of mental hygiene would comprise the following interrelated positive dimensions (Table 1): (1) diet and nutrition; (2) physical exercise; (3) sleep and rest; (4) courage; (5) work-leisure balance; (6) personal relationships; (7) values and intentionality; (8) being mode; (9) prosocial behavior; and (10) attitude towards life.

Table 1. Proposed Dimensions for a Clinical Concept of "Mental Hygiene"

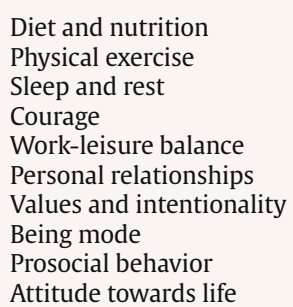

In the next paragraphs, we briefly address each of the aforementioned dimensions of mental hygiene, which may be useful in the behavioral treatment of depressed patients. 


\section{Diet and Nutrition}

Studies in nutritional psychiatry have been gathering increasing evidence for the association between a healthy diet and mental well-being. Deficiencies in vitamins have been related to different psychological problems and a diet rich in fruits and vegetables has been linked with higher levels of happiness. Contrary to a regular consumption of junk food, adherence to a Mediterranean diet has been associated with a reduced risk of depression (Lai et al., 2014).

\section{Physical Exercise}

Exercise is a leading behavioral intervention to alleviate symptoms of depression (Lawlor \& Hopker, 2001). The link between the practice of physical exercise and the reduction of depressive symptoms has been suggested to be mediated by increased release of endorphins, reduced levels of cortisol, distraction from worries and depressing thoughts, and improved self-efficacy.

\section{Sleep and Rest}

Sleep disturbances are core symptoms of depression. Depressed patients who experience difficulty sleeping tend to report cumulative problems, such as irritability, distractibility, and tiredness. Sleep deficiency leads to increased levels of inflammatory markers and impairs the regulation of serotonin transmission related to threat processing (Fang et al., 2019). Sleep hygiene includes noise reduction, regular sleep schedule, and avoidance of psychostimulant substances (e.g., caffeine) and daytime napping.

\section{Courage}

Courage can be seen as the opposite to experiential, emotional avoidance (e.g., procrastination). Psychological definitions describe courage as resulting from the interaction of experiencing fear, bearing in mind one's higher purpose, and taking action to pursue valued goals (Goud, 2005). Essentially, courage represents a resource for choosing growth over safety needs. In fact, courage is a compassionate attribute that can be developed through healthy risk-taking and comfort zone expansion (e.g., engaging in challenging activities).

\section{Work-Leisure Balance}

Unemployment duration influences the onset and course of depressive symptoms. However, excessive job involvement is a predictor of burnout and may serve a generalized function of emotion regulation, which in turn may block the development of other life roles (cf. Iacovides et al., 2003). The engagement in meaningful leisure activities provides an antidote for the negative effects of stress in daily life, as well as valued opportunities for selfactualization.

\section{Personal Relationships}

Social support is positively linked to a wide array of health outcomes. Social belonging is a fundamental human need, and experiencing genuine support from others (especially significant others) is vital for emotional development. Family, friends, intimate partners, neighbors, and colleagues provide unique responses to our emotional, informative, and instrumental support needs. There is ample evidence for the buffering effect of social support on the link between adversity and depressive symptoms (Ozbay et al., 2007).

\section{Values and Intentionality}

In behavioral terms, values are defined as desired overall qualities of ongoing action. Contrary to goals, values are not achievable and thus require enduring cultivation. The clarification and/or the development of values are crucial for one's ability to experience a meaningful life (Wilson \& Murrell, 2004). The cultivation of a compassionate intentionality (towards others and ourselves) facilitates the adoption of value-driven behaviors (e.g., courageous behavior) that counteract the urge of emotion-driven behavior (e.g., impulsivity or avoidance).

\section{Being Mode}

This is a core concept in mindfulness-based cognitive therapy (Williams, 2008), and is contrary to the mind's default "doing mode". The doing mode involves worrying about the future or the past, and continuously comparing how things are and how they are expected to be. The overactivation of the doing mode prompts self-criticism and rumination (e.g., Sanz-Blasco, 2017). The "being mode", on the other hand, enables a direct and intimate experience of the present, and is inherently non-striving and non-judgmental. The cultivation of the being mode is likely to facilitate detached mindfulness ("nevermind my mind") and emotional acceptance (negative and positive emotions).

\section{Prosocial Behavior}

Prosocial behaviors are voluntary actions to benefit others. A small but growing body of research shows that "doing good for others is doing good for ourselves"; specifically, prosocial behaviors and motives have been linked to increased well-being, happiness, and social acceptance (Raposa et al., 2015). From an evolutionary perspective, it is worth noting that prosocial and affiliative interactions are major regulators of threat processing (Gilbert, 2015), thus highlighting their importance in preventing and alleviating psychological suffering.

\section{Attitude towards Life}

The ubiquity of human suffering and the uncertainties of life may lead us to experience existential crises. The daily experience of negative emotional states (e.g., sadness, anger, fear, and despair) is most often normal, natural, and harmless. Those emotional experiences become problematic when an individual tries to directly control them (e.g., by ruminating) or engages in mood-driven behavior. Instead, distraction and problem-solving in response to negative mood are more efficient in decreasing depressive symptoms (Nolen-Hoeksema, 2001). Of course, philosophical reflections are important, but the context in which they occur may lead to unintended consequences. Maintaining a practical, easygoing, hopeful, and humorous outlook on life is a wise attitude to live it fully.

Altogether, we suggest from our clinical experience that the concept and the proposed working definition of mental hygiene may be of great utility in the effective implementation of BA therapeutic protocols. First, it provides a metaphor (akin to "personal hygiene") for autonomy in psychological self-care that is helpful and easy to understand. Second, it conveys a sense of common humanity (universal needs) that facilitates "de-shaming" in building rapport during case formulation in depression. Third, it outlines an intuitive rationale for treatment and relapse prevention based on behaviors that can be trained or untrained in therapy. Given its comprehensive nature, this concept of mental hygiene may be applicable across the lifespan, notwithstanding developmental specificities and age-appropriate adjustments. Despite its conjectured clinical 
and heuristic value, construct validity of the concept of "mental hygiene" as defined herein should be desirably examined in future psychometric studies.

\section{Conflict of Interest}

The authors of this article declare no conflict of interest.

\section{Acknowledgements}

We are especially grateful to Charlotte Handford for her idiomatic review of the manuscript. We are thankful to Prof. Dr. Cristina Canavarro for her encouragement and to Dr. J. Matos as a never-ending source of inspiration. This paper is dedicated to the greatly missed Prof. Dr. Adriano Vaz-Serra.

\section{References}

Chartier, I. S., \& Provencher, M. D. (2013). Behavioural activation for depression: Efficacy, effectiveness and dissemination. Journal of Affective Disorders, 145(3), 292-299. https://doi.org/10.1016/j. jad.2012.07.023

Cummings, E. M., Davies, P. T., \& Campbell, S. B. (2000). Developmental psychopathology and family process: Theory, research and clinical implications. The Guilford Press.

Fang, H., Sheng, T., Sheng, J., \& Shao, A. (2019). Depression in sleep disturbance: A review on a bidirectional relationship, mechanisms and treatment. Journal of Cellular and Molecular Medicine, 23(4), 23242332. https://doi.org/10.1111/jcmm.14170

Gilbert, P. (2015). Affiliative and prosocial motives and emotions in mental health. Dialogues in Clinical Neuroscience, 17(4), 381-389. https://doi. org/10.31887/DCNS.2015.17.4/pgilbert

Goud, N. H. (2005). Courage: Its nature and development. The Journal of Humanistic Counseling, Education and Development, 44(1), 102-116. https://doi.org/10.1002/j.2164-490X.2005.tb00060.x

Headey, B. W., Kelley, J., \& Wearing, A. J. (1993). Dimensions of mental health: Life satisfaction, positive affect, anxiety and depression. Social Indicators Research, 29(1), 63-82. https://doi.org/10.1007/BF01136197

Iacovides, A., Fountoulakis, K., Kaprinis, S., \& Kaprinis, G. (2003). The relationship between job stress, burnout and clinical depression. Journal of Affective Disorders, 75(3), 209-221. https://doi.org/10.1016/ S0165-0327(02)00101-5

Jacobson, N. S., Martell, C. R., \& Dimidjian, S. (2001). Behavioral activation treatment for depression: Returning to contextual roots. Clinical
Psychology: Science and Practice, 8(3), 255-270. https://doi. org/10.1093/clipsy/8.3.255

Keyes, C. L. M. (2002). The mental health continuum: From languishing to flourishing in life. Journal of Health and Social Behavior, 43(2), 207222. https://doi.org/10.2307/3090197

Lai, J. S., Hiles, S., Bisquera, A., Hure, A. J., McEvoy, M., \& Attia, J. (2014). A systematic review and meta-analysis of dietary patterns and depression in community-dwelling adults. The American Journal of Clinical Nutrition, 99(1), 181-197. https://doi.org/10.3945/ajcn.113.069880

Lawlor, D. A., \& Hopker, S. W. (2001). The effectiveness of exercise as an intervention in the management of depression: Systematic review and meta-regression analysis of randomised controlled trials. The British Medical Journal, 322(7289), 763-767. https://doi.org/10.1136/ bmj.322.7289.763

Lejuez, C. W., Hopko, D. R., LePage, J. P., Hopko, S. D., \& McNeil, D. W. (2001). A brief behavioral activation treatment for depression. Cognitive and Behavioral Practice, 8(2), 164-175. https://doi.org/10.1016/S10777229(01)80022-5

Lorenzo-Luaces, L., \& Dobson, K. (2019). Is Behavioral Activation (BA) more effective than cognitive therapy (CT) in severe depression? A reanalysis of a landmark trial. International Journal of Cognitive Therapy, 12, 1-10. https://doi.org/10.1007/s41811-019-00044-8

Nolen-Hoeksema, S. (1991). Responses to depression and their effects on the duration of depressive episodes. Journal of Abnormal Psychology, 100(4), 569-582. https://doi.org/10.1037/0021-843X.100.4.569

Ozbay, F., Johnson, D. C., Dimoulas, E., Morgan, C. A. III, Charney, D., \& Southwick, S. (2007). Social support and resilience to stress: From neurobiology to clinical practice. Psychiatry, 4(5), 35-40.

Raposa, E., Laws, H., \& Ansell, E. (2015). Prosocial behavior mitigates the negative effects of stress in everyday life. Clinical Psychological Science, 4(4), 691-698. https://doi.org/10.1177/2167702615611073

Sanz-Blasco, R. (2017). The emotional information processing approach in the treatment of psychological disorders: The metacognitive therapy. Clínica y Salud, 28(1), 47-48. https://doi.org/10.1016/j. clysa.2016.07.002 1130-5274

Stein, A. T., Carl, E., Cuijpers, P., Karyotaki, E., \& Smits J. A. J. (2020) Looking beyond depression: A meta-analysis of the effect of behaviora activation on depression, anxiety, and activation. Psychological Medicine, 1-14. https//doi.org/10.1017/S0033291720000239

Sünbül, Z. A., Malkoç, A., Gördesli, M. A., Arslan, R., \& Çekici, F. (2018). Mindful self-care dimensions as agents of well-being for students in mental health fields. European Journal of Education Studies, 5(5), 3341. https://doi.org/10.5281/zenodo.1469657

Williams, M. (2008). Mindfulness, depression and modes of mind. Cognitive Therapy and Research, 32(6), 721-733. https://doi.org/10.1007/ s10608-008-9204-z

Wilson, K. G., \& Murrell, A. R. (2004). Values work in acceptance and commitment therapy: Setting a course for behavioral treatment. In S. C. Hayes, V. M. Follette, \& M. M. Linehan (Eds.), Mindfulness and acceptance: Expanding the cognitive-behavioral tradition (pp. 120151). Guilford Press. 
